\title{
Relationship between global solar radiation and sunshine hour duration for Bida in Nigeria
}

\author{
Godfrey Nnaegbo Okonkwo ${ }^{1, *}$, Anthony Osita Chibuike Nwokoye ${ }^{2}$ \\ ${ }^{1}$ Department of Science Laboratory Technology, The Federal Polytechnic, Bida \\ ${ }^{2}$ Department of Physics and Industrial Physics, Nnamdi Azikiwe University, Awka
}

Email address:

godfreyok1@yahoo.com (G. N. Okonkwo),ositonyk@yahoo.com (A. O. C. Nwokoye)

\section{To cite this article:}

Godfrey Nnaegbo Okonkwo, Anthony Osita Chibuike Nwokoye. Relationship between Global Solar Radiation and Sunshine Hour Duration for Bida in Nigeria. International Journal of Renewable and Sustainable Energy. Vol. 3, No. 2, 2014, pp. 43-46.

doi: $10.11648 /$ j.jirse.20140302.12

\begin{abstract}
The global solar radiation and sunshine hour duration measured over a period of thirteen years (2000 - 2012), were used to establish an Angstrom-type correlation equation (model) for estimating total solar radiation falling on a horizontal surface in Bida (lat. $9.1^{\circ} \mathrm{N}$, long. $6.02^{\circ} \mathrm{E}$ ). Six other existing correlations involving global solar radiation and sunshine duration were also used to estimate the global solar radiation for Bida and their results were compared with the model used in this paper. From the close agreement exhibited between the measured and estimated values, it was evident that this model showed better results than the existing models.
\end{abstract}

Keywords: Global Solar Radiation, Sunshine Hour Duration, Existing Models

\section{Introduction}

Sunshine duration or sunshine hours is a climatological indicator, measuring duration of sunshine in a given period for a given location on earth (typically, expressed as an average of several years). It is a measure of cloudiness of a location [1]. Bright sunshine hours at a given location vary significantly due to atmospheric components and it is measured by sunshine recorders.

It has been shown that, among the atmospheric and meteorological parameters that affect the amount of global solar radiation reaching a horizontal location, the greatest influence is exerted by sunshine hours [2]. The first correlation equation (model) using the sunshine duration data for estimating the monthly mean daily global solar radiation on a horizontal surface was proposed in 1924 [3]. Soon after, [4] modified the model to a more convenient form as:

$$
\frac{\bar{H}_{M}}{\overline{\bar{H}}_{O}}=a+b\left(\frac{\bar{n}}{\bar{N}}\right)
$$

where $\bar{H}_{M}$ is the measured global solar radiation (MJm ${ }^{2}$ day $\left.^{-1}\right), \bar{H}_{O}$ is the monthly mean daily extraterrestrial radiation $\left(\mathrm{MJm}^{-2} \mathrm{day}^{-1}\right), \bar{n}$ is the monthly mean daily bright sunshine hours, $\bar{N}$ is the maximum possible monthly mean daily sunshine hours or the day length, and a and $b$ are regression constants.

Many other researchers have demonstrated the predictive ability of the Angstrom-Prescott one-parameter equation correlating the global solar radiation to the relative sunshine hours at different locations [2, 5-14].

The objective of this paper is to develop the AngstromPrescott sunshine hour linear model for predicting the monthly mean daily global solar radiation on a horizontal surface in Bida. The result of this correlation is compared with the results of six other commonly used one-parameter linear correlations.

\section{Materials and Methods}

The monthly mean daily global solar radiation and sunshine duration data measured in Bida for thirteen years (2000-2012) were obtained from the Nigerian Meteorological Agency, Bida $\left(9.1^{\circ} \mathrm{N}, 6.02^{\circ} \mathrm{E}\right)$. The global solar radiation was measured with a Gunn-Bellani radiometer and so the data were converted to $\mathrm{MJm}^{-2} \mathrm{day}^{-1}$ using the conversion factor of $1.216\left(\mathrm{MJm}^{-2} \mathrm{day}^{-1}\right)$ proposed by [15]. A computer software programme, IBM SPSS20, was used to determine the regression constants of equation (1) by correlating the measured solar radiation data with the relative sunshine data. 
The maximum possible monthly mean daily sunshine hours or day length is given by [16] as:

$$
\bar{N}=\frac{2}{15} \omega_{s}
$$

where $\omega_{s}$ is the hour angle, expressed as:

$$
\omega_{s}=\cos ^{-1}(-\tan \varphi \tan \delta)
$$

where, $\varphi$ and $\delta$ are the latitude and declination angles, respectively. The declination $\delta$ is given by:

$$
\delta=23.45 \sin \left(360\left(\frac{N+284}{365}\right)\right)
$$

where $\mathrm{N}$ is the day number of the year. The monthly mean daily extraterrestrial radiation $\bar{H}_{O}$ on horizontal surface is given by the expressed:

$$
\bar{H}_{O}=\frac{24}{\pi} I_{s c} E_{o}\left(\frac{\pi}{180} \omega_{s} \sin \varphi \sin \delta+\cos \varphi \cos \delta \sin \omega_{s}\right)
$$

where $\mathrm{I}_{\mathrm{sc}}$ is the solar constant in $\left(\mathrm{MJm}^{-2} \mathrm{day}^{-1}\right)$. The value of $I_{s c}$ used in this study is $4.921 \mathrm{MJm}^{-2} \mathrm{day}^{-1} . \mathrm{E}_{\mathrm{o}}$ is the eccentricity correction factor of the Earth's orbit. The value of $E_{o}$ is given by [17]:

$$
E_{o}=1+0.033 \cos \left(\frac{360 N}{365}\right)
$$

The result of our model was compared with six other reported models. The six models are:

Rietveld's model (18): Akpabio [11] quoted Rietveld's correlation, which is believed to be applicable anywhere in the world, given as:

$$
\frac{\bar{H}_{M}}{\overline{\bar{H}}_{O}}=0.18+0.62\left(\frac{\bar{n}}{\bar{N}}\right)
$$

Turton's model [19] which developed average regression constants for the humid tropical countries given as:

$$
\frac{\bar{H}_{M}}{\overline{\bar{H}}_{O}}=0.30+0.40\left(\frac{\bar{n}}{\bar{N}}\right)
$$

Fagbanle's model [7]: A model which is believed to be applicable anywhere in Nigeria according to [11] given as:

$$
\frac{\bar{H}_{M}}{\bar{H}_{O}}=0.31+0.42\left(\frac{\bar{n}}{\bar{N}}\right)
$$

Arinze and Obi's model [5]: A model which is believed to be applicable to Northern Nigeria:

$$
\frac{\bar{H}_{M}}{\overline{\bar{H}}_{O}}=0.20+0.77\left(\frac{\bar{n}}{\bar{N}}\right)
$$

Glover and McCulloch's model [20]: A model which introduced a latitude effect to one of the Angstrom-Prescott coefficients, as quoted by [2] and [11]:

$$
\frac{\bar{H}_{M}}{\bar{H}_{O}}=0.29 \cos \varphi+0.52\left(\frac{\bar{n}}{\bar{N}}\right)
$$

for Minna environment:

$$
\frac{\bar{H}_{M}}{\overline{\bar{H}}_{O}}=0.2460+0.4276\left(\frac{\bar{n}}{\overline{\bar{N}}}\right)
$$

These six models listed, were also separately applied to the sunshine data at Bida to estimate the monthly mean daily global solar radiation on a horizontal surface in Bida. The results from these models were compared with the measured global solar radiation to find the best correlation for Bida environment.

\section{Results and Discussions}

Table 1 is the statistical test results of the models. It is observed that our model yielded the lowest mean bias error (MBE), root mean square error (RMSE) and mean percentage error (MPE) values and hence is the best model for Bida and other similar environments. The low RMSE value is a measure of accuracy of a model. From Table 1, it is also observed that the MBE values of four models (Rietveld, Turton, Fagbanle and Akinbode) are negative, indicating under-estimation. The models with positive MBE values (Arinze and Obi, Glover and McCulloch) indicate over-estimation. In the same vein, positive and negative MPE values indicate over-estimation and underestimation, respectively. It is desirable that MBE and MPE values should be low $[11,14]$.

The transmissivity of the atmosphere for global solar radiation under perfectly clear sky conditions is given as the sum of the regression coefficients, $(a+b)$ while the transmissivity of an overcast atmosphere is interpreted as the intercept, a, [2, 11].

From our regression constants $(a=0.11$ and $b=0.79)$, it is observed that the atmospheric transmissivity under clear sky for Bida is 0.90. This result compares well with the values of 0.80 and 0.74 quoted by [2] for Dakar, Senegal. However, this figure is a little higher than the range $(0.68-$ $0.75)$ reported for most tropical regions [21, 22]. The high figure of 0.90 explains the reason why Bida has an arid climate characterized by very little rainfall.

Table 2 is the comparison between measured and predicted global solar radiation at Bida. The result shows that our model is most suitable for predicting the monthly mean daily global solar radiation, from monthly mean daily sunshine hours in locations with similar weather patterns as Bida in Nigeria. It is observed that the percentage error between the measured and predicted values did not exceed $6 \%$ and, in general is very low. Again from Table 2, it is shown that the values of the clearness index, $\mathrm{K}_{\mathrm{T}}(0.39-$ 0.70), for the atmosphere in Bida is generally clear throughout the year. This indicates that a reasonable portion of the global solar radiation is direct beam. This also explains the level of harshness of the weather experienced in this area.

Akinbode's model [8]: A correlation that was developed 
Table 1. Statistical test results of the various models applied for Bida

\begin{tabular}{lccccc}
\hline & \multicolumn{2}{c}{ Regression constants } & \multicolumn{3}{c}{ Statistical error indicators } \\
Models & $\mathbf{a}$ & $\mathbf{b}$ & MBE & RMSE & MPE \\
\hline Our model & 0.11 & 0.79 & 0.0029 & 0.6451 & -0.11257 \\
Rietveld (7) & 0.18 & 0.62 & -0.85379 & 1.2055543 & 4.111128 \\
Turton (8) & 0.30 & 0.40 & -0.77023 & 1.660549 & 3.233056 \\
Fagbanle (9) & 0.31 & 0.42 & -0.0331 & 1.440562 & -0.65617 \\
Arinze and Obi (10) & 0.20 & 0.77 & 2.715684 & 2.8054766 & -14.6177 \\
Glover and McCulloch (11) & 0.29 & 0.52 & 1.037891 & 1.5781 & -6.17075 \\
Akinbode (12) & 0.2460 & 0.4276 & -2.16783 & 2.543207 & 10.736 \\
\hline
\end{tabular}

Table 2. Comparison between measured and predicted values of global solar radiation for Bida

\begin{tabular}{|c|c|c|c|c|c|c|c|c|}
\hline Month & $\begin{array}{c}\bar{n} \\
(\mathbf{h r s})\end{array}$ & $\begin{array}{c}\bar{N} \\
\text { (hrs) }\end{array}$ & $\begin{array}{l}\bar{n} \\
\overline{\bar{N}}\end{array}$ & $\begin{array}{c}\bar{H}_{M} \\
\left(\mathbf{M J m}^{-2} \text { day }^{-1}\right)\end{array}$ & $\begin{array}{c}\bar{H}_{O} \\
\left(\mathbf{M J m}^{-2} \text { day }^{-1}\right)\end{array}$ & $\begin{array}{c}\overline{\boldsymbol{H}}_{p} \\
\left(\mathbf{M J m}^{-2} \mathbf{d a y}^{-1}\right)\end{array}$ & $\overline{\boldsymbol{K}}_{T}=\frac{\overline{\boldsymbol{H}}_{M}}{\overline{\boldsymbol{H}}_{O}}$ & $\begin{array}{c}\text { Error } \\
\%\end{array}$ \\
\hline Jan. & 6.9 & 11.5 & 0.6012 & 18.6 & 32.3 & 19.03 & 0.5744 & 2.31 \\
\hline Feb. & 7.0 & 11.7 & 0.5971 & 21.0 & 34.7 & 20.32 & 0.6044 & -3.24 \\
\hline Mar. & 6.9 & 12.0 & 0.5757 & 21.7 & 37.2 & 21.12 & 0.5840 & -2.67 \\
\hline Apr. & 6.8 & 12.2 & 0.5543 & 20.4 & 38.0 & 20.92 & 0.5370 & 2.55 \\
\hline May & 6.1 & 12.4 & 0.4935 & 19.3 & 37.6 & 18.89 & 0.5135 & -2.12 \\
\hline Jun. & 5.9 & 12.5 & 0.4695 & 18.2 & 36.7 & 17.77 & 0.4944 & -2.36 \\
\hline Jul. & 5.5 & 12.5 & 0.4392 & 16.0 & 36.9 & 16.96 & 0.4330 & 6.00 \\
\hline Aug. & 4.5 & 12.3 & 0.3630 & 15.0 & 37.6 & 15 & 0.3993 & 0.00 \\
\hline Sep. & 5.1 & 12.0 & 0.4254 & 16.9 & 37.1 & 16.63 & 0.4551 & -1.60 \\
\hline Oct. & 7.1 & 11.8 & 0.5988 & 19.7 & 35.3 & 20.68 & 0.5599 & 4.97 \\
\hline Nov. & 8.4 & 11.6 & 0.7242 & 21.9 & 32.7 & 22.43 & 0.6703 & 2.42 \\
\hline Dec. & 7.2 & 11.5 & 0.6290 & 20.3 & 31.4 & 19.18 & 0.6456 & -5.52 \\
\hline
\end{tabular}

Figure 1 shows that in the overall average years (2000 2012), there were two maxima (major and minor) and two corresponding minima (major and minor) [11]. The major maximum occurred in the month of November during the dry season (November - April) and minor maximum occurred between February and March. The major minima occurred between July and September during the rainy season (May - October) while the minor minimum occurred in the month of January due to the harmattan dust haze that covers the atmosphere at that period of the year.

The best month, November, with $\mathrm{H}$ value of 21.9 (MJm ${ }^{2}$ day $^{-1}$ ) contributed 9.6\% and worst month, August, with $\mathrm{H}$ value of $15.0 \mathrm{MJm}^{-2} \mathrm{day}^{-1}$ contributed $6.6 \%$ of the annual total. The result also shows that global solar radiation values for Bida are between 15.0 and $22 \mathrm{MJm}^{-2} \mathrm{day}^{-1}$.

Figure 1, also shows that high values of global solar radiation are obtained during the dry season while low values are obtained during the rainy season due to rain bearing clouds that pervade the sky.

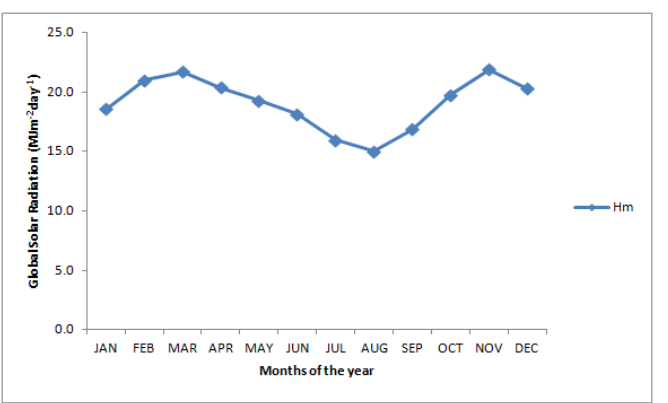

Figure 1. Monthly mean daily global solar radiation (2000-2012)
Figure 2 is the monthly variation of mean daily sunshine duration for the thirteen year period $(2000-2012)$. It is observed that the same trend is followed here as in Figure 1. Hence the explanation and reason is the same as that of Figure 1 due to the fact that sunshine duration has direct correlation with global solar radiation.

The linear regression equation with its constants, obtained for this work is given as:

$$
\frac{\bar{H}_{M}}{\overline{\bar{H}}_{O}}=0.11+0.79\left(\frac{\bar{n}}{\bar{N}}\right)
$$

This correlation can also be applied for predicting the global solar radiation in other locations in Nigeria with similar weather conditions.

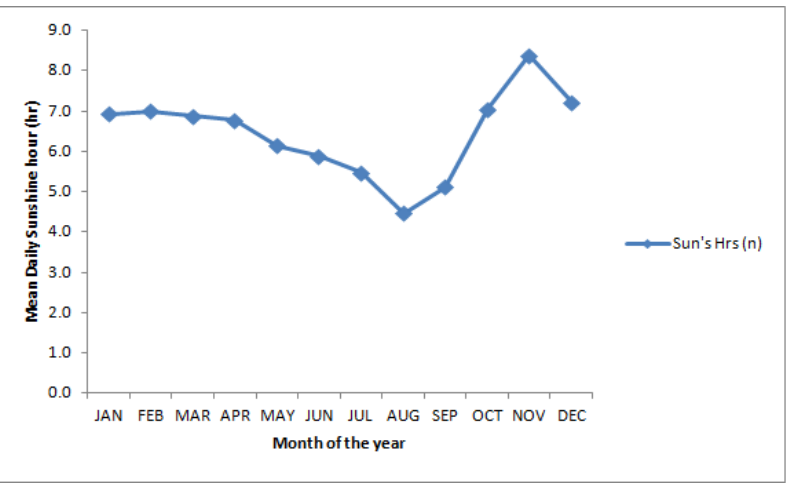

Figure 2. Monthly mean daily sunshine duration (2000 - 2012) versus month of the year 


\section{Conclusion}

It has been established that sunshine duration has direct correlation with global solar radiation. The linear regression analysis of the global solar radiation and sunshine duration data by means of the least-squares technique presents our model as the best correlation for the Bida location. Therefore, the monthly mean daily global solar radiation falling on horizontal surfaces in Bida, Nigeria, may be estimated by the correlation:

$$
\frac{\bar{H}_{M}}{\bar{H}_{O}}=0.11+0.79\left(\frac{\bar{n}}{\bar{N}}\right)
$$

There was a good agreement between the measured values and predicted data using this model.

It was also shown that, the global solar radiation at Bida exhibits monthly and seasonal variation, with two maxima (major and minor) in November and February - March, respectively. It also indicated two minima (major and minor) in the months of July - September and January, respectively.

This results in two types of global solar radiation at Bida. First, the high irradiation values in the dry season associated with long duration of sunshine hours (above 6.5 hrs/day) and less cloudy skies. Second, the low irradiation values are obtained in the rainy season (when rain bearing clouds pervade the sky) associated with least sunshine hours (less than $5 \mathrm{hrs} /$ day).

\section{References}

[1] Wikipedia, Sunshine duration, http://en.wikipedia.org/wiki/ Sunshine_duration (Retrieved, 24/02/2014).

[2] S.O. Udo, "Contribution to the Relationship Between Solar Radiation and Sunshine Duration in the Tropics: A Case Study of Experimental Data at Ilorin, Nigeria,” Turk J. Phys, vol. 26 , pp $229-236,2002$.

[3] A.S. Angstrom, "Solar and Terrestrial. Radiation," Meteorol. Soc., vol. 50, pp 121 - 126, 1924.

[4] J.A. Prescott, "Evaporation from a water Surface in relation to Solar Radiation," Tran. R. Soc. S. Austr., vol. 64, pp 114 $-118,1940$.

[5] E.A. Arinze and S.E. Obi, "Solar Energy Availability and Prediction in Northern Nigeria," Nig. J. Solar Energy, vol. 3: pp 3 - 10, 1983.

[6] A.S. Sambo, "Solar Radiation in Kano: A Correlation with Meteorological Data,” Nig. J. Solar Energy, vol. 1, pp 59 64, 1985.

[7] R.O. Fagbanle, "Estimation of total solar radiation in
Nigeria, using meteorological data," Nig. J. Ren. Energy, vol. 1, pp 1-10, 1990.

[8] F.O. Akinbode, "Solar Radiation in Minna: Correlation with Meteorological Data,” Nig. J. Ren. Energy, vol. 3 (1\&2), pp $9-17,1992$.

[9] F.W. Burari and A.S. Sambo, "Models for the Prediction of Global Solar Radiation for Bauchi using Meteorological Data," Nig. J. Ren. Energy, vol. 91, pp 30 - 33, 2001.

[10] F.W. Burari, A.S. Sambo and E.D. Mshelia, "Estimation of Global Solar Radiation in Bauchi," Nig. J. Ren. Energy, vol. 9 (1 \& 2), pp $34-36,2001$.

[11] L.E. Akpabio and S.E. Etuk, "Relationship Between Global Solar Radiation and Sunshine Duration for Onne, Nigeria," Turk J. Phys, vol. 27, pp $161-167,2003$.

[12] L.E. Akpabio, S.O. Udo and S.E. Etuk, "Modeling Global Solar Radiation for a Tropical Location: Onne, Nigeria," Turk J. Phys, vol. 29, pp $63-68,2005$.

[13] A. Chukwuemeka and M.N. Nnabuchi, "Solar Radiation in Port Harcourt: Correlation with Sunshine Duration," Pacific J. Sc. Tech., vol. 10 (1), pp 681 - 685, 2009.

[14] C. Augustine and M.N. Nnabuchi, "Analysis of some meteorological data for some selected Cities in the Eastern and Southern zone of Nigeria," African J. Environ. Sc. Tech. Vol. 4 (2), pp 92 -99, 2010.

[15] J.C. Ododo, "New Models for the Prediction of Solar Radiation in Nigeria, Paper presented at the $2^{\text {nd }}$ OAU/STRC Conference on New, Renewable and Solar Energies," at Bamako Mali, 16 - 20 May, 1994.

[16] M. Igbal, An Introduction to Solar Radiation, Academy Press: New York, 1983.

[17] K.N. Liou, Introduction to Atmospheric Radiation. Academy Press, New York, 1980.

[18] M.R. Rietveld, "A new method for estimating the regression coefficients in the formula relating solar radiation to sunshine," Agric. Met., vol. 19, pp 243 - 252, 1978.

[19] S.M. Turton, "The relationship between total irradiation and sunshine duration in the humid tropics," Solar Energy, vol. 38 , pp $353-354,1987$.

[20] J. Glover and J.S.G. McCulloch, "The Empirical relation between solar radiation and hours of sunshine," Q.J.R. Met. Soc., vol. 84, pp $172-175,1958$.

[21] A.S. Sambo, "Empirical models for the correlation of global solar radiation with meteorological data for Northern Nigeria," Solar and Wind Technology, vol. 3, pp $89-93$, 1986.

[22] L.E. Akpabio, "Comparison between Solar Radiation Energy and the Characteristics of Wind Power Calculations in South Eastern Nigeria,” Nig. J. Phys., vol. 4, pp $15-20$, 1992. 